\title{
Authors' 2015 additions to the IOC consensus statement: Relative Energy Deficiency in Sport (RED-S)
}

\author{
Margo Mountjoy, ${ }^{1}$ Jorunn Sundgot-Borgen, ${ }^{2}$ Louise Burke, ${ }^{3}$ \\ Susan Carter, ${ }^{4}$ Naama Constantini, ${ }^{5}$ Constance Lebrun, ${ }^{6}$ \\ Nanna Meyer, ${ }^{7}$ Roberta Sherman, ${ }^{8}$ Kathrin Steffen, ${ }^{2,9}$ \\ Richard Budgett, ${ }^{9}$ Arne Ljungqvist ${ }^{9}$
}

\begin{abstract}
In April 2014, the International Olympic Committee (IOC) published a Consensus Statement in this journal entitled "Beyond the Female Athlete Triad: Relative Energy Deficiency in Sport (RED-S)". ${ }^{1}$ In reference to that Consensus Statement, Professor Mary Jane De Souza and colleagues published an editorial (July 2014). ${ }^{2}$ The editorial below expands on the original Consensus Statement and comments on the 2014 Editorial by Professor Mary Jane De Souza and colleagues.
\end{abstract}

\section{RELATIVE ENERGY DEFICIENCY IN SPORT (RED-S)}

Albert Einstein said: "The important thing is to never stop questioning." A group of 11 IOC authors have called attention, as others in the past, ${ }^{3}{ }^{4}$ to a problem that is wider and more complex than originally identified when the term 'Female Athlete Triad' (Triad or FAT) was first coined in 1992. Just as knowledge evolves, so too should ideas and constructs on how to address it.

Given the evolution of science since 1992, and to more accurately describe the clinical syndrome originally known as the Female Athlete Triad, the IOC introduced a more comprehensive, broader term: Relative Energy Deficiency in Sport.

\footnotetext{
${ }^{1}$ Department of Family Medicine, Michael G. DeGroote School of Medicine, McMaster University, Hamilton, Ontario, Canada; ${ }^{2}$ Department of Sports Medicine, The Norwegian School of Sport Sciences, Oslo, Norway; ${ }^{3}$ Department of Sports Nutrition, Australian Institute of Sport, Belconnen, Australia; ${ }^{4}$ University of Northern Colorado, University of Colorado Medical School, Colorado, USA; ${ }^{5}$ Orthopedic Department, HadassahHebrew University Medical Center, Jerusalem, Israel; ${ }^{6}$ Department of Family Medicine, Faculty of Medicine \& Dentistry, Glen Sather Sports Medicine Clinic, University of Alberta, Edmonton, Alberta, Canada; ${ }^{7}$ Health Sciences Department, University of Colorado, Colorado Springs, Colorado, USA; ${ }^{8}$ The Victory Program at McCallum Place, St. Louis, Missouri, USA; ${ }^{9} \mathrm{IOC}$ Medical and Scientific Department, Lausanne, Switzerland

Correspondence to Margo Mountjoy, Department of Family Medicine, Michael G. DeGroote School of Medicine, McMaster University, Hamilton, Ontario, Canada; mmsportdoc@mcmaster.ca
}

The syndrome of RED-S refers to impaired physiological functioning caused by relative energy deficiency, and includes but is not limited to impairments of metabolic rate, menstrual function, bone health, immunity, protein synthesis, and cardiovascular health.

Our April 2014 Consensus statement identifies the aetiological factor underpinning the syndrome as:

an energy deficiency relative to the balance between dietary energy intake and the energy expenditure required to support homeostasis, health and the activities of daily living, growth and sporting activities.

We reaffirm the principle that the IOC Consensus Statement highlights about energy deficiency/low energy availability among exercising people. De Souza and colleagues' editorial criticises the use of the word 'balance,' suggesting that the IOC authors have confused the terms energy availability and energy balance. We used the term 'balance' in the context of comparing two items which are not necessarily equal. To clarify, the underlying aetiology of RED-S is the same as that which underpins the Triad-low energy availability. The reason we chose the term RED-S-Relative Energy Deficiency in Sport-is to recognise that low energy availability can occur in the presence of energy balance.

\section{To clarify:}

The cause of the Relative Energy Deficiency in Sport is the scenario termed 'low energy availability', where an individual's dietary energy intake is insufficient to support the energy expenditure required for health, function and daily living, once the costs of exercise and sporting activities are taken into account.

\section{LIMITATIONS OF THE TERMINOLOGY 'FEMALE ATHLETE TRIAD'-WHY IT'S OVERDUE FOR A 'REBRAND'}

The understanding of the Triad has strengthened over the past three decades because people were brave enough to
Relative Energy Deficiency in Sport

Key Definitions:

Energy balance: ${ }^{6}$ Energy Balance is the amount of dietary energy added to or lost from the body's energy stores after all of the body's physiological systems have completed their work for the day. $(E B=$ Energy intake-Total energy expenditure)

Energy deficit: Energy deficit is the discrepancy in energy balance when dietary energy intake is less than total energy expenditure, such that energy is lost from the body's energy stores and/or compensatory mechanisms take place to reduce total energy expenditure. Energy availability:: ${ }^{6}$ Energy availability is the amount of dietary energy remaining to support remaining metabolic systems in the body after the energy cost for a particular system has been removed: In the case of athletes, energy availability is the amount of energy remaining to support all other body functions after the energy expended in exercise and sporting activities is removed from energy intake. ( $E A=$ Energy intake-Energy expended in exercise)

Low energy availability: ${ }^{6}$ Low energy availability occurs when an individual's dietary energy intake is insufficient to support the energy expenditure required for health, function and daily living, once the cost of exercise and sporting activities is taken into account. Relative Energy deficiency: Relative energy deficiency connotes that low energy availability can occur even in the scenario where energy intake and total energy expenditure are balanced (ie, there is no overall energy deficit). Relative Energy Deficiency in Sport: ${ }^{1}$ The syndrome of RED-S refers to impaired physiological functioning caused by relative energy deficiency, and includes but is not limited to impairments of metabolic rate, menstrual function, bone health, immunity, protein synthesis and cardiovascular health.

stand up and describe a problem with some apparent features that needed urgent and focused investigation. Parts of the original model have been updated over time with new knowledge, and the sports medicine and exercise science community has embraced this evolution rather than insisting that the Triad be invalidated because the details have changed. In fact, 
if one applied a pedantic critique of the Triad, many of the criticisms levelled at RED-S could also apply to it:

A. Female: scientific publications clearly demonstrate that relative energy deficiency also affects men. ${ }^{7-24}$

B. Athlete: by identifying the 'athlete' in the title, the Female Athlete Triad fails to account for recreational exercisers and dancers who would not identify themselves as athletes but who can develop relative energy deficiency.

C. Triad:

1. The literature describes many more than two negative outcomes of low energy availability, so it either is not really a triad or it ignores/ undervalues these other issues.

2. According to many studies, athletes have one or two of the three traditional components of the triad, so it is not a true triad.

3. De Souza and colleagues' editorial states that it can continue to call the syndrome a triad because the three corners (low energy availability/menstrual dysfunction/poor bone health) are the most serious parts. However, it is unclear what criteria are used to justify this assessment and why other aspects of the health/performance impairments associated with low energy availability do not merit topline recognition.

4. The term 'Triad' does not prioritise the key element. When the 'Triad' was first coined, investigators were not aware that energy deficiency was the key problem. Subsequently, Anne Loucks and others have provided compelling data on the preeminence of energy deficiency as the causative element. Why confuse trainees, health professionals and athletes by referring to a 'triad' when the culprit is not osteoporosis, not amenorrhoea (two elements of the 'triad' as coined in 1992) but energy deficiency? Hence the recommendation of 'Relative Energy Deficiency in Sport (RED-S)'.

D. The Female Athlete Triad acronym (FAT): While researchers and clinicians involved in the work of Female Athlete Triad refer to it as 'Triad,' many others refer to it as 'FAT,' an unfortunate acronym.

E. Female Athlete Triad Model: The present model/diagram and description fail to portray the interrelatedness of all the factors, the concern about subclinical levels of presentation, and the concern if all three issues are not involved. Thus, it does not accurately describe the complexity of the syndrome.

\section{MALE ATHLETES ARE AFFECTED-IT IS IRREFUTABLE}

Although most studies related to RED-S have been performed on female athletes, there is a growing body of evidence that the negative sequelae of low energy availability also occur in male athletes from leanness-demanding or weight category sports, and in scenarios of high volume training. ${ }^{8}$ In particular, these male athletes also have an increased risk of disordered eating, ${ }^{9-11}$ disruption of Gonadotrophin Releasing Hormone and Luteinizing hormone $(\mathrm{GnRH})$ and LH pulsatility, as well as lower sex hormone levels, ${ }^{12-18}$ impaired reproductive function, ${ }^{20} \quad 14 \quad 21$ decreased immunity ${ }^{11}$ and impaired bone health. ${ }^{22-24}$

It is certainly possible, as hypothesised in DeSouza and colleagues' editorial, that male athletes have a different set of issues, outcomes and modifying factors involved in these observations. However, the IOC authors believe that these health issues need attention, rather than being ignored because they seem less defined.

The original version of the Triad proposed that clinical outcomes of disordered eating, amenorrhoea and osteoporosis were always involved. The subsequent published model now recognises that this may not be the case, and that we still need to be concerned about female athletes whose energy availability, menstrual function and/or bone health are suboptimal, even if not yet a clinically recognised problem. So why are we discounting problems of male athletes because of a hypothesis that they may not be as 'serious' as those of female athletes? Any level of suboptimal body function caused by inadequate energy intake is a potential issue worthy of study and needing the attention of athletes/coaches/professionals. As knowledge grows, the discussion and recommendations for different groups can evolve.

The hypothesis that low energy availability/energy deficiency is not as important for men because they do not have the same energetic cost of reproduction to defend also raises questions about whether the Triad is problematic for women outside the reproductive age. Do we stop worrying about premenarcheal and postmenopausal women with low energy availability? If energy availability is low, it will reduce the capacity for some type of body function, activity and/or performance. Therefore, since energy deficiency and eating disorders seem to have many similar physiological and health impairing effects in men as they do in women, it is time to broaden the concept to include men as well as women. Indeed, the Olympic Charter, which documents the fundamental principles of Olympism, provides clear direction regarding human rights in sport and, in particular, against discrimination on the basis of gender:

\begin{abstract}
"The practice of sport is a human right. Every individual must have the possibility of practicing sport, without discrimination of any kind......Any form of discrimination with regard to a country, or a person on grounds of race, religion, politics, gender or otherwise is incompatible with belonging to the Olympic Movement." 25
\end{abstract}

The Olympic Movement Medical Code goes even further, underscoring the obligation to avoid gender discrimination in the provision of medical care of athletes:

"Athletes should receive such health care as appropriate to their needs....Services should be continuously available and accessible to all equitably, without discrimination." 26

The current IOC leadership has repeatedly underscored their commitment to the protection of athlete health (women and men). ${ }^{27}$

\section{RED-S HEALTH AND PERFORMANCE CONSEQUENCES}

There is always a challenge in developing a simple model for handling complex, multifactorial problems. The RED-S conceptual models of potential Health and Performance Consequences of relative energy deficiency are designed for simplicity of understanding the main principle of the underpinning aetiology of RED-S, which is placed in the centre of the hub and spoke' model. The conceptual models are also designed to show a plethora of physical, psychological and potential performance sequelae that develop as a result of energy deficiency, regardless of their relative importance. The chief purpose of the models is to serve as a clinical teaching tool for athletes and coaches to demonstrate the numerous health consequences of relative energy deficiency, as well as the performance consequences, which are a priority for them.

The RED-S conceptual models are not designed to illustrate either the complex interactions of physiological and psychological factors involved in the process or the interconnectivity among the functions and mechanisms involved in the syndrome. Indeed, these synergistic and antagonistic process mechanisms are also not captured in the current Triad model. ${ }^{28}$ As knowledge of 


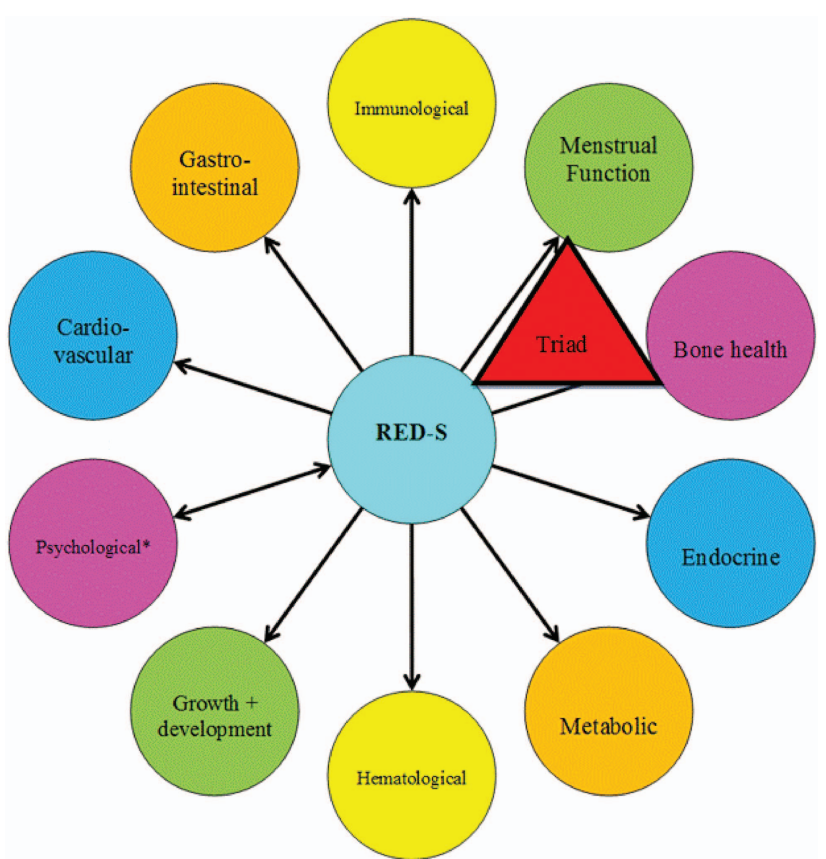

Figure 1 Health Consequences of Relative Energy Deficiency in Sport (RED-S) ( ${ }^{*}$ Psychological consequences can either precede RED-S or be the result of RED-S). the interactions of the functional processes of RED-S advances, the IOC Consensus Statement authors will embrace the expected evolution of the RED-S conceptual models of the Health and Performance Consequences (figures 1 and 2). ${ }^{29}$

\section{RED-S RISK ASSESSMENT AND RETURN TO PLAY MODELS}

The RED-S 'Red Light-Yellow LightGreen Light' Risk Assessment and Return to Play (RTP) models are designed to take a complex clinical assessment and RTP decision-making process and integrate them into a functional model that is simple to understand by the athlete and the clinician, as well as relatively easy to implement in the 'real world'. The challenge of designing a functional model to better manage complex clinical scenarios arises in all areas of medicine. Clinicians want guiding principles to assist with

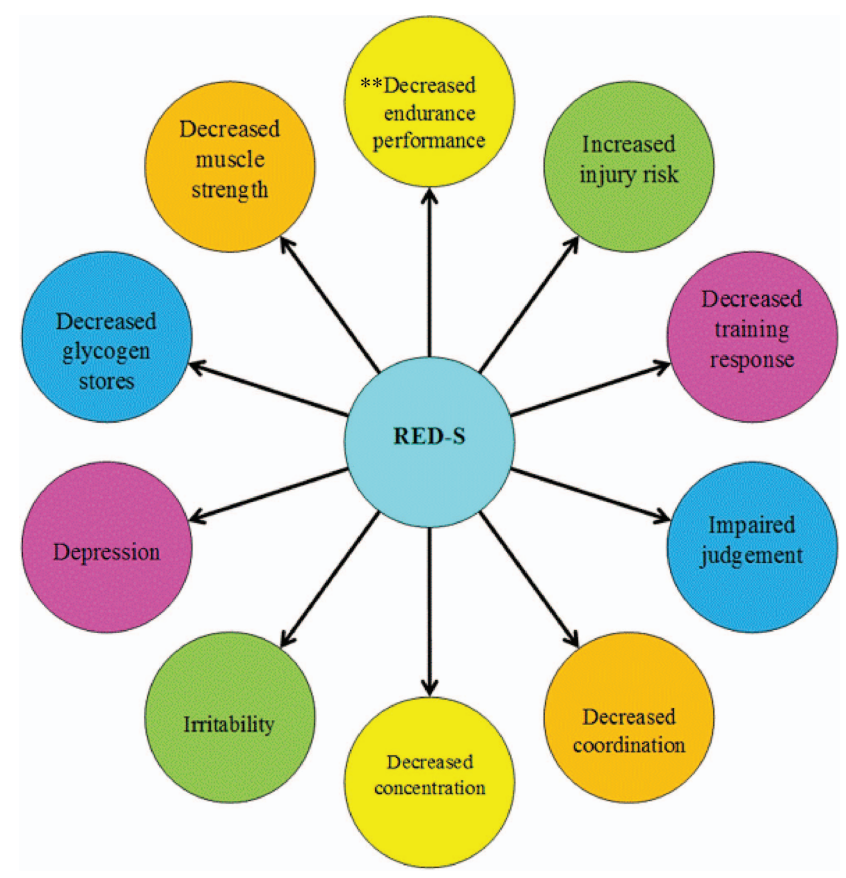

Figure 2 Potential Performance Effects of Relative Energy Deficiency in Sport (**Aerobic and anaerobic performance). medical management and harm minimisation. All models have limitations, but they are designed with latitude in the interpretation of an individual's situation by experts, acknowledgement of mitigating factors, ongoing monitoring of the individual, and continual re-evaluation of the model.

The RED-S 'Red Light-Yellow LightGreen Light' Risk Assessment and Return to Play models were developed with this flexibility to allow clinicians in the field the ability to adapt the model to their particular athlete situation. For example, the specific length of 'prolonged period with low energy availability' is not provided in the RED-S model because there are no studies indicating the time frame an athlete can experience energy deficit without compromising health and performance. However, it is the experience and belief of the IOC authors that treating clinicians' knowledge of the sport-specific demands and case-specific parameters, combined with their clinical experience, is sufficient for them to be able to adapt their particular clinical scenario to the RED-S models to facilitate a safe RTP decision. In fact, the models presented in the IOC Consensus Statement for Risk Assessment and RTP have been developed and implemented for more than 2 years at the competitive level, for all ages and sport disciplines of athletes at the Norwegian Olympic Training Center. ${ }^{30}$ These models have already been demonstrated to be successful in practice.

The models were developed to be adaptable for men and women. The end points identified as red light 'high risk' criteria and yellow light 'caution' criteria apply to male and female athletes, except for the two end points related to the menstrual cycle. Since there are many different methods to estimate body composition and the SE of measurements can be high (as high as 5\% and higher for commonly used field methods if not standardised) ${ }^{31}$ depending on the method and standardisation used, it is difficult to specify the lower limit of body fat for male and female elite athletes, even though the general guidelines recommend $>5 \%$ body fat for men and $10 \%$ for women. ${ }^{31}$

To further support clinicians in the field with the management of RED-S athletes, the IOC authors have developed a RED-S Clinical Assessment Tool (RED-S CAT) modelled after the Sport Concussion Assessment Tool (SCAT-3), ${ }^{32}$ which is widely used in clinical practice. Like the original SCAT, the RED-S CAT is a starting point to facilitate clinical practice and to encourage further research and 
validation; it is expected to evolve over time as the body of science in the field grows. The RED-S CAT is also published in this issue (see page 421).

\section{FUTURE DIRECTIONS}

The IOC authors of the Consensus Statement on RED-S recommend that the sports medicine and sport science communities gain an increased understanding and awareness of the broadened concept of RED-S. The RED-S conceptual models should be integrated into performance nutrition educational approaches, as they offer an opportunity for athletes and coaches to understand the broad scope of issues related to suboptimal eating practices. The RED-S CAT should be implemented globally to facilitate and improve the medical management of male and female athletes.

DeSouza and colleagues are correct that the body of published research on RED-S is not yet as robust as that on the Triad. Indeed, most of the Triad research was done AFTER the term was coined. It is a recommendation of the IOC authors, as written in the IOC Consensus paper, that the scientific experts in the field work collaboratively to further enhance our understanding of:

- The aetiology and best treatment of athletes with RED-S, including men and women, able-bodied and disabled populations, and individuals of various races.

- The design and validation of tools to accurately measure energy availability in the clinical setting.

- The validation of screening tools (such as the RED-S CAT), prevention and treatment programmes.

In summary, it is evident that the term 'Female Athlete Triad' is not only inaccurate, but also inadequate to describe the syndrome. As the underlying aetiology is low energy availability, the coining of new, more comprehensive terminology 'relative energy deficiency in sport' (RED-S) is introduced by the IOC following a robust review and debate of the current science base. It is also time to acknowledge and address the health and performance of the male athlete who also suffers from RED-S. It is time for change.

$$
\begin{array}{r}
\text { "Progress is not possible without change." } \\
\text { George Bernard Shaw }
\end{array}
$$

Contributors MM and JS-B were involved in substantial contributions to conception and design, drafting and revising the manuscript and the final version to be published. $L B, S C, N C, C L, N M, R S$ and $\mathrm{KS}$ were involved in the contribution to design, revising the manuscript and the final version to be published.
$R B$ and $A L$ were involved in the review of the final version to be published.

Competing interests None.

Provenance and peer review Commissioned; externally peer reviewed.
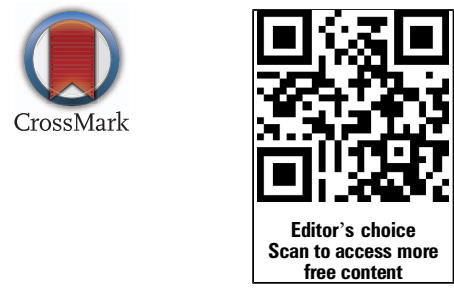

To cite Mountjoy M, Sundgot-Borgen J, Burke L, et al. Br J Sports Med 2015;49:417-420.

Accepted 17 January 2015

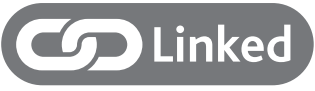

- http://dx.doi.org/10.1136/bjsports-2014-094559

Br J Sports Med 2015;49:417-420.

doi:10.1136/bjsports-2014-094371

\section{REFERENCES}

1 Mountjoy M, Sundgot-Borgen J, Burke L, et al. The IOC consensus statement: beyond the Female Athlete Triad-Relative Energy Deficiency in Sport (RED-S). Br J Sports Med 2014;48:491-7.

2 DeSouza MJ, Williams NI, Nattiv A, et al. Misunderstanding the female athlete triad: refuting the $\mathrm{IOC}$ consensus statement, beyond the female athlete triad — relative energy deficiency in sport (RED-S). Br J Sports Med 2014;48:1461-5.

3 Wheatley S, Khan S, Szekely AD, et al. Expanding the female athlete triad concept to address a public health issue. Perf Enhancement Health 2012;1:10-27

4 Temme K, Hoch A. Recognition and rehabilitation of the female athlete triad/tetrad: a multidisciplinary approach. Curr Sports Med Rep 2013;12:190-9.

5 Loucks $A B$. Energy balance and energy availability. In: Maughan, $R$, ed. Sports nutrition. 1st edn. Vol XIX 2014:72-87.

6 Loucks $A B$, Kiens $B$, Wright HH. Energy availability in athletes. J Sports Sci. 2011:29(Suppl 1):S7-15.

7 Dolan $\mathrm{E}, \mathrm{O}^{\prime}$ Connor $\mathrm{H}, \mathrm{O}^{\prime}$ Loughlin $\mathrm{G}$, et al. Nutritional, lifestyle and weight-control practices of professional jockeys. J Sports Sci 2011;29:791-9.

8 Filaire E, Rouveix M, Pannafieux C, et al. Eating attitudes, perfectionism and body-esteem of elite male judoists and cyclists. I Sports Sci Med 2007:6:50-7.

9 Goltz FR, Stenzel LM, Schneider CD. Disordered eating behaviors and body image in male athletes. Rev Bras Psiquiatr 2013;35:237-42.

10 Bratland-Sanda S, Sundgot-Borgen J. Eating disorders in athletes: overview of prevalence, risk factors and recommendations for prevention and treatment. Eur $J$ Sport Sci 2013;13:499-508.

11 Dolan E, McGoldrick A, Davenport C, et al. An altered hormonal profile and elevated rate of bone loss are associated with low bone mass in professional horse-racing jockeys. J Bone Miner Metab 2012;30:534-42.

12 MacConnie SE, Barkan A, Lampman RM, et al. Decreased hypothalamic gonadotropin-releasing hormone secretion in male marathon runners. $N$ Engl J Med 1986;315:411-17.
13 Ayers JW, Komesu V, Romani T. et al Anthropomorphic, hormone, and psychologic correlates of semen quality in endurance trained male athletes. Fertil Steril 1985:43:917-21.

14 Hackney AC, Sinning WE, Bruot BC. Reproductive hormonal profiles of endurance-trained and untrained males. Med Sci Sports Exerc 1988:28:180-9.

15 Hackney $A C$, Sinning WE, Bruot BC Hypothalamic-pituitary-testicular axis function in endurance-trained males. Int I Sports Med 1990;11:298-303.

16 Wheeler GD, Wall SR, Belcastro AN, et al. Reduced serum testosterone and prolactin levels in distance runners. JAMA 1984;252:514-16.

17 Opstad PK. Androgenic hormones during prolonged physical stress, sleep, and energy deficiency. J Clin Endocrinol Metab 1992;74:1176-83.

18 Hamalainen EK, Adlercreutz H, Puska P, et al. Decrease of serum total and free testosterone during a low fat high-fibre diet. I Steroid Biochem 1983:18:369-70.

19 De Souza MJ, Miller BE. The effect of endurance training on reproductive function in male runners. A "volume threshold" hypothesis. Sports Med 1997:23:357-73.

20 Cumming DC, Wheeler GD, McColl EM. The effects of exercise on reproductive function in men. Sports Med 1989;7:1-17.

21 Tsai M, Chou K, Chang C, et al. Changes of mucosal immunity and antioxidation activity in elite male Taiwanese taekwondo athletes associated with intensive training and rapid weight loss. $\mathrm{Br} J$ Sports Med 2011;45:729-34.

22 Bennell KL, Brukner PD, Malcolm SA. Effect of altered reproductive function and lowered testosterone levels on bone density in male endurance athletes. $\mathrm{Br} J$ Sports Med 1996:30:205-8.

23 Guillaume G, Chappard D, Audran M. Evaluation of the bone status in high-level cyclists. J Clin Densitometry 2012;15:103-7.

24 Olmedillas H, Gonzalez-Aguero A, Moreno LA, et al. Bone related health status in adolescent cyclists. PLOS ONE 2011;6:e24841.

25 Fundamental Principles of Olympism: \# 4 and 6. in The Olympic Charter. 2011.

26 Care and Treatment: \# 5.1. in The Olympic Movement Medical Code. 2009.

27 Engebretsen L, Bahr R, Cook JL, et al. The IOC Centres of Excellence bring prevention to sports medicine. Br J Sports Med 2014;48:1270-5.

28 Nattiv A, Loucks AB, Manore MM, et al. American College of Sports Medicine position stand. The female athlete triad. Med Sci Sports Exerc 2007;39:1867-82.

29 Constantini NW. Medical concerns of the dancer. Book of Abstracts, XXVII FIMS World Congress of Sports Medicine; Budapest, Hungary, 2002:151.

30 Skårderud F, Fladvad T, Holmlund $\mathrm{H}$, et al. The malnourished athlete-guidelines for interventions. Tidsskr Nor Laegeforen 2012;132:1944. http://www. olympiatoppen.no/fagomraader/idrettsernaering/ Fagstoff/page6827.html (4.6. 2012).

31 Ackland TR, Lohman TG, Sundgot-Borgen J, et al. Current status of body composition assessment in sport: review and position statement on behalf of the ad hoc research working group on body composition health and performance, under the auspices of the I. O.C. Medical Commission. Sports Med 2012;42:227-49.

32 SCAT-3. http://bjsm.bmj.com/content/47/5/259.full. pdf (accessed 22 Sep 2014). 